\title{
Using a College Curriculum to Integrate Informal Science Learning Opportunities for University and Middle School Students
}

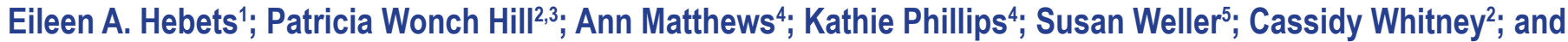 \\ Tyler B. Corey ${ }^{1}$ \\ ${ }^{1}$ School of Biological Sciences, ${ }^{2}$ Methodology and Research Core (MERC) Facility, and ${ }^{3}$ Department of Sociology, University of Nebraska-Lincoln, Lincoln, Nebraska; \\ ${ }^{4} 21$ st Century Community Learning Centers, Lincoln, Nebraska; and ${ }^{5}$ niversity of Nebraska State Museum, Lincoln, Nebraska
}

Keywords: Service-Learning, Out-of-School Time, Afterschool, Informal Science Learning (ISL), Science Museum

Publication Date: August 20. 2020

DOI: https://doi.org/10.15695/jstem/v3i2.07

\begin{abstract}
We used community partnerships to develop an integrated science-learning program focused on two groups of learners - university and middle school (MS) students - to increase students' interest and confidence in science as well as motivation to pursue science. Key program elements include a university course for undergraduate and graduate students, university student-led weekly afterschool clubs held at local middle schools (mostly Title I), and a capstone museum science festival led by university and MS students. Across nine course offerings, 78 university students conducted 25 clubs at seven middle schools and engaged at least 240 MS students. The capstone science festival engaged $\sim 1,200$ public participants across six events. We evaluated the program in two phases. Quantitative and qualitative assessments show that university students enjoyed the course and increased their ability to describe complex scientific phenomenon to youth. Middle school students reported significant increases in science interest, science understanding, and understanding scientists (1st evaluation phase); and increased interest in a career in science and in their perception of others seeing them as a scientist (2nd phase). Consistent with prior research, overall we found an increase in interest and understanding of science, science identity, and interest in future science careers for MS students.
\end{abstract}

\section{INTRODUCTION}

The United States lags behind other industrialized countries in developing a comprehensive and inclusive science, technology, engineering, and mathematics (STEM) workforce (Atkinson and Mayo, 2010). To address this problem, the American Association for the Advancement of Science (AAAS) has called for "Vision and Change" in university-level biology education in order to make science learning a more active endeavor for students, and to broaden the reach of science education to students of all backgrounds (AAAS, 2011, 2015, 2018). In response to calls for reform in science education, there has been an increased focus on developing and testing new pedagogical practices, shifting learning objectives to meet real-world challenges, and rigorous assessment of best practices in science education across universities (AAAS, 2011, 2015, 2018; Metz and McLaughlin, 2016).

Research exploring university students' experiences within the STEM field suggests that certain factors are key ingredients in retaining students' interest and participation, including (a) science learning, (b) science identity, and (c) confidence in science-related skills (Graham et al., 2013; Hazari et al., 2013; Hill et al., 2017). Science learning, identity, and confidence, in turn, are known to increase in response to university-level educational interventions that incorporate (i) early and active learning experiences and (ii) engagement in learning communities (Graham et al., 2013; Linn et al., 2015), creating a positive feedback loop (Figure 1).

Addressing STEM persistence in higher education by implementing educational interventions and institutional change is clearly an important goal, yet the breakdown of STEM persistence begins in the elementary and middle school years, long before students reach academies of higher education (e.g. Murphy and Beggs, 2003). Early adolescence is a time when science interest and science identity decline, particularly among underrepresented groups (Blue and Gann, 2008; Hill et al., 2018; Sorge, 2007; Tan et al., 
2013). As such, early adolescence is an opportune time to intervene and provide youth programming that prevents, or minimizes, such drop-offs. Toward this end, understanding and increasing STEM proficiency, interest, identities, and inclusivity among adolescents has become a primary goal of researchers, educators, policymakers, and employers.

\section{Service-Learning Opportunities in Higher Education.} Service-learning is one way for institutes of higher education to share science with a broader community of people, including adolescents in middle schools. Service-learning is an educational experience in which service projects are integrated into course content and learning objectives rather than completed in addition to coursework (e.g. Furco, 1996). Students who participate in service-learning courses engage in structured activities that meet educational goals as well as specific needs within the community. The service component of coursework becomes meaningful as students reflect on their experience to further understand course content, appreciate their discipline, and enhance their sense of civic responsibility (Bringle and Hatcher, 1995).

Service-learning has been successfully incorporated into higher education courses across fields such as Psychology (Bringle et al., 2016), Human Development and Family Studies (Weiler et al., 2013), Public Health (Mackenzie et al., 2019), Engineering (Mclean et al., 2019), Ecology (McGinley, 2018), and Chemistry (Najmr et al., 2018; Sewry and Paphitis, 2018), among others. Although the goals of each service-learning course or project may differ, they often share the common purpose of reaching beyond the university 'walls' to involve community members in learning or in project work.

There are several ways to approach service-learning in higher education, allowing for flexibility in course design and management, and different ways for students to engage in their communities. For example, instructors of service-learning courses may forge partnerships with local non-profit and state organizations to deliver services or education (Yusop and Correia, 2014), task students with developing and implementing lesson plans for K-12 students, (McGinley, 2018), or organize mentorships of at-risk youth (Weiler et al., 2013). Though the approaches may vary, service-learning offers students opportunities to share their knowledge as well as develop themselves personally and professionally.

Service-learning is known to boost university students' learning and civic engagement. For instance, university students may gain increased social awareness and civic responsibility (Huda et al., 2018; Sewry and Paphitis, 2018), greater academic content mastery, and improved communication and problem-solving skills (McGinley, 2018). Notably, service-learning opportunities can also increase STEM undergraduate students' confidence in collaborating and commu- nicating with diverse audiences, potentially influencing their persistence in the STEM field (Woodley et al., 2019).

Communities also benefit from students' engagement in service-learning programs. For example, low-resourced communities may gain quality (in)formal educational programming (Woodley et al., 2019), or access to professional-level services from students at no cost (Yusop and Correia, 2014). Further, when scientists and STEM (under)graduate students engage in their communities through service-based learning (Sewry and Paphitis, 2018), they can increase the impacts of science communication, for example by engaging youth as future scientists (Hebets, 2018). Ultimately, programs that use university-level service-learning courses to engage K-12 youth in informal STEM learning have the potential to positively affect communities and students at multiple levels simultaneously.

Afterschool Programming. Afterschool hours represent an important time for reaching young students. Nationally, approximately 8.4 million students participate in programs that take place during out-of-school hours each year. Children who are underrepresented in STEM careers attend these programs in high numbers (African American $=24 \%$; Hispanic $=16 \%$; and Native American $=16 \%$ ), compared to the national average of $15 \%$ (Krishnamurthi et al., 2014). Thus, afterschool programs represent a potential avenue to reach the very students that could build a more inclusive STEM field, and to increase the amount of time that students are exposed to science-related ideas and experiences. This is particularly important in light of shrinking allowances for science education during in-school hours (Blank, 2013).

Out-of-school time is especially valuable in providing youth with hands-on, practical experiences with STEM-related concepts (Afterschool Alert, 2010; Afterschool Alliance, 2016). Afterschool time that is directed toward science education can also facilitate open-ended, exploratory STEM challenges that build students' confidence in scientific exploration and that allow students to envision themselves as scientists. This is especially true when afterschool programming is high quality and when students are actively engaged in learning (e.g. Shernoff, 2010).

Given that service-learning courses facilitate meaningful connections between universities and surrounding communities, and that afterschool programming at community schools may be an important avenue to reach young students, blending these two educational structures in an integrated science-learning community may be an effective way to increase multiple generations of student-interest and persistence in STEM.

Program Aims. Our program aimed to increase student interest and confidence in, as well as motivation to pursue science through participation in a science-learning community 
created by integrating a university-level service-learning course with afterschool programming for adolescents. To meet this aim, we developed (I) a service-learning course, Communicating Science through Outreach (CSO) in which university students implemented quality afterschool science programming - specifically, (II) weekly science clubs to middle school (MS) students - in local high need schools (mostly Title 1). The goal was to provide integrated opportunities for increased science learning, motivation, confidence, and for building a science-identity among students at multiple educational levels - university and MS. To that end, our program design incorporated evidence-based research findings regarding STEM persistence from higher education (Graham et al. 2013), and research related to interest and achievement in STEM among middle school students (e.g. Murphy and Beggs, 2003; Yang et al., 2016).

Importantly, this program used existing educational structures (university coursework and afterschool programs) to deliver programming. In doing this, we conceptualized that the program could be sustainable even without specialized funding.

Program Conceptualization. We hypothesized that if we gave both university and MS students (a) fun, engaging, opportunities for science learning (i.e. increase science learning) along with (b) opportunities to take ownership of their learning and engage in a science community with peers (i.e. increase science identity), then students would demonstrate more confidence in science and motivation to pursue science (Figure 1). We predicted that these increases would be present for both university and MS students. A similar model of integrated science learning was shown to be successful in several NSF-funded GK12 programs (Ufnar et al. 2012).

In addition to educational aims, we hypothesized that we could create a sustainable model of science learning interaction across educational units (university and MS) by building a new service-learning course that facilitates partnerships with local formal and informal STEM education collaborators. Once we created the course, and built and strengthened associated relationships, we predicted that the program would be sustainable without additional funding, provided sufficient university student interest to fill the course and sufficient MS interest in the afterschool club.

\section{METHODS}

Program Overview. Our integrated science-learning program included three main elements. (I) A newly developed university course for graduate and undergraduate students - Communicating Science through Outreach (CSO) - that we offered through the School of Biological Sciences at the University of Nebraska-Lincoln. (II) Weekly afterschool science clubs - Creative Science Investigation (CSI) - that CSO

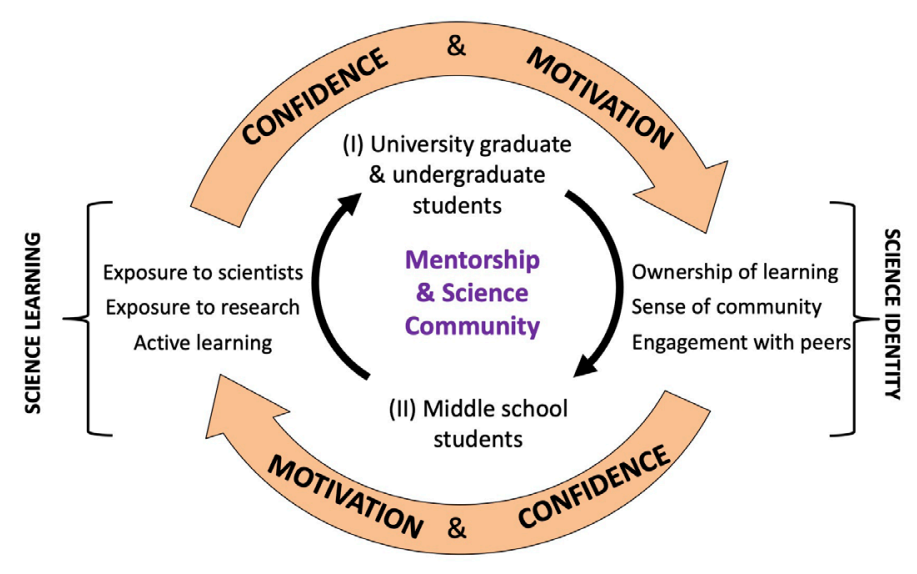

Figure 1. Adaptation of the 'persistence framework' (Graham et al., 2013) demonstrating our hypothesis that (I) university and (II) middle school youth's Confidence in and Motivation to pursue, science will increase following participation in our integrated science learning program. The three key program elements - I - Communicating Science through Outreach course, II - Creative Science Investigation afterschool club for MS students, and III - Sunday with a Junior Scientist all incorporate science-learning opportunities (e.g. exposure to scientists, exposure to research, active learning), opportunities to increase science identity (e.g. ownership of learning, sense of community, engagement with peers) and most importantly, mentorship and a science community.

students conducted at select middle schools. (III) A capstone community science festival - Sunday with a Junior Scientist (SWJS) - operated by teams of CSO and MS students and hosted at the University of Nebraska State Museum.

To date, we offered the CSO course nine times. In total, 78 university students (CSO students hereafter) participated (Table 1). CSO students developed and implemented 25 semester-long afterschool clubs at seven different middle schools (five of which were Title I schools), and engaged more than $240 \mathrm{MS}$ students in informal science learning (Table 1). More than 1,180 people attended SWJS across six events (Table 1).

The program received initial funding from a two-year grant from the National Science Foundation - Informal Education with Arachnids - funded through the Connecting Researchers and Public Audiences (CRPA) program (DRL 1241482, 2012 - 2013, to EAH). The team later received two small yearlong grants from the Nebraska Department of Education (2016-2017; 2017-2018) to extend the programs reach to include elementary school students [see II. Afterschool Clubs - Creative Science Investigation (CSI)]. Despite only receiving two years of initial funding, the program has continued running for eight years; five years past its initial funding period.

Key Partnerships and Sustainability. A close collaboration among key partners - the University of Nebraska-Lincoln's 
Table 1. Numbers of Participants Impacted by Our Three Key Program Elements. (I) Communicating Science through Outreach (CSO) course (Semester/YR; instructor; \# students); (II) Creative Science Investigation (CSI) afterschool club (\# middle schools, \# MS students); (III) Sunday with a Junior Scientist (SWJS) (\# of attendees).

\begin{tabular}{llcccccc}
\hline Semester and Year & Instructor & \# Undergrads & \# Grads & Total Students & Middle Schools $^{\mathbf{1}}$ & \# MS Students & attending SWJS $^{\mathbf{2}}$ \\
\hline Spring 2013 & EAH & 6 & 7 & 13 & D, G, M, L, P & 40 & NA \\
Fall 2013 & EAH & 4 & 2 & 6 & D, M & 25 & NA \\
Fall 2014 & EAH & 7 & 5 & 12 & D, G, M & 27 & NA \\
Fall 2016 & EAH & 4 & 6 & 10 & C, P, D/PH & 67 & 278 \\
Spring 2017 & AA & 2 & 2 & 4 & C, P & $\sim 25$ & 288 \\
Fall 2017 & EAH & 3 & 2 & 5 & C, P & $\sim 25$ & $95^{*}$ \\
Fall 2018 & EAH & 5 & 4 & 9 & G, M, P & 34 & 194 \\
Spring 2018 & TBC & 7 & 0 & 7 & P, C & 23 & 146 \\
Spring 2019 & TBC & 9 & 3 & 12 & M, P, D & 24 & 180 \\
\hline Totals & & $\mathbf{4 7}$ & $\mathbf{3 1}$ & $\mathbf{7 8}$ & $\mathbf{2 5}$ clubs & $\mathbf{2 4 0}$ & $\mathbf{1 1 8 1}$ \\
\hline
\end{tabular}

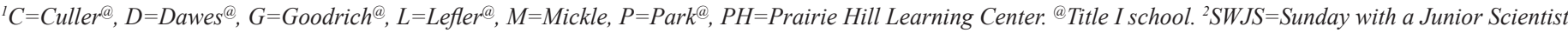
"This event was hosted on a Thursday night instead of the typical Sunday afternoon.

School of Biological Sciences (SBS), the Lincoln Public Schools (LPS), the 21st Century Community Learning Centers (CLC), a federally funded program that serves children and families in Title I schools (Holstead and King, 2011), and the University of Nebraska State Museum (UNSM) was at the core of the program. Prior to implementing our program, there were already strong relationships between some, but not all, of these partners. For example, Dr. James Blake, the K-12 science curriculum specialist at LPS at the time, worked hard to establish and maintain a good working relationship with the Lincoln CLCs, as he saw the CLCs as a partner and resource for engaging more students in the STEM fields. Dr. Blake recently stated, "I know that what students can do for one brief class period in a short lesson during the school day - the same students can spend days on it after school because of the lack of state standards taking up the instructional time." Importantly, the university was able to easily partner with both LPS and the Lincoln CLCs due to the productive and supportive partnership that they had already established.

Partnerships among the key stakeholders enabled the program to continue beyond the initial funding period. In particular, SBS was able to add a teaching assistantship position to the CSO course, which allowed graduate students to teach the course in semesters that the faculty instructor (EAH) was unable to teach due to other teaching commitments. EAH, an active research scientist, taught the course six times and two different $\mathrm{PhD}$ students taught the course the additional three times (Table 1). Notably, the UNL SBS course offerings now include the CSO course, which fills one of the general education requirements.

Local CLC sites contributed additional funding that paid for CLC staff at afterschool sites and for transportation to field trips. The CLC district office also supported a graduate assistantship through UNL's Department of Child, Youth, and Family Studies who helped to coordinate afterschool clubs, communicate with partners, and conduct some of the evaluation. Finally, the UNSM supported event logistics such as event promotion, staffing, and the event set-up and takedown. The museum also provided free admission to the SWJS festival days, by directing a portion of its annual donations fund to pay for staff time and other costs.

\section{Key Programmatic Elements.}

I. Communicating Science through Outreach (CSO). During this semester-long 3-credit course, university undergraduate and graduate students learned about informal science education/learning, science communication more generally, and developed and implemented afterschool programming for local MS students. The course aimed to familiarize university students with inquiry-based learning paradigms and strategies for communicating science to general audiences. To that end, CSO students spent time learning relevant content in class and spent time outside of class conducting afterschool programs in middle schools. See Table 2 for specific course learning objectives (see Supplemental Materials for course syllabus).

CSO students spent the first several weeks of the course engaged in reading and discussing topics related to informal science learning and science communication (e.g. Dudo and Besley, 2016; Hebets, 2018). Additionally, in an effort to better prepare CSO students for their upcoming interactions with MS students, education professionals visited the course to lead discussions about MS student physical, mental and emotional development, and about different learning styles. The CSO students also visited the UNSM where a museum educator provided instruction on effective practices to promote inquiry and informal science learning in a museum environment. 
Table 2. Communicating Science through Outreach Course Learning Objectives.

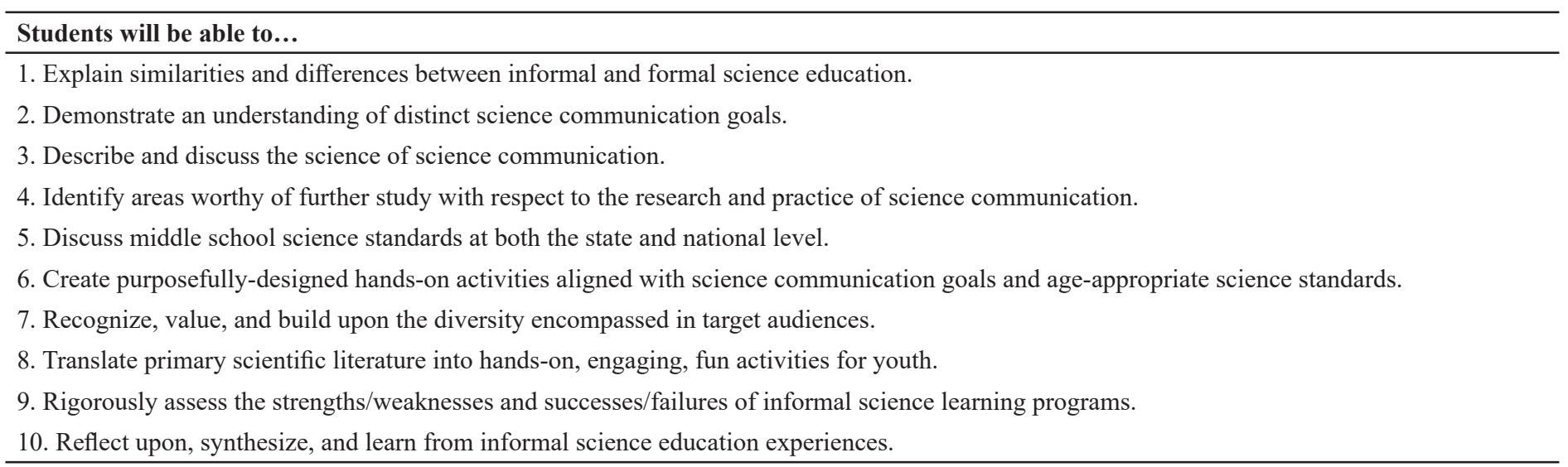

Preparing for CSO-MS Interactions. Preparing the CSO students for their work with the MS students was a key contributing factor to the success of this project. The CSO students participated in a learning process that required them to reflect on their own development during their middle school years. They identified specific characteristics during those years in the areas of physical development, personal/ social growth, mental ability, interests, and general mental well-being. A guest presenter (KP, a Curriculum Specialist for Lincoln CLCs) facilitated discussions with the students regarding their personal responses about their MS years. She also shared research about characteristics of the typical middle schooler. Further discussion enabled the students to learn what to expect from MS learners, and how to best engage them.

In the weeks before the clubs began, KP also introduced CSO students to the concept of how students learn. CSO students completed learning style inventories (4-MAT; McCarthy, 1990) that enabled them to examine their own learning style preferences, to understand that people learn in different ways, and to realize that successful educators need to integrate a variety of teaching strategies to ensure that all learners have access to the material in a manner that best fits them. This information, paired with the 'characteristics of the MS learner' discussions helped the CSO students as they prepared to engage their MS students in fun enrichment opportunities. Additionally, for several CSO courses (whenever possible based upon CLC club schedules and staff availability), prior to the start of their own club, CSO students attended other afterschool clubs to observe facilitator-MS interactions.

Group/Club Formation. The course instructor grouped students into teams of 3 or 4 according to their interests and schedules after the first weeks of the course. Then, they matched each team with a middle school where the CSO team provided afterschool science programming for the remainder of the semester $(8-12$ weeks). Thereafter, CSO students implemented an afterschool club once per week at their respective MS and attended class on their home campus twice per week; a reduction of one class period from the beginning of the semester. Once clubs began, CSO students used in-class time to present potential club activities to classmates who provided valuable feedback and suggestions for modification/revisions. This was also a time for students to discuss challenges/opportunities experienced during their club time. Each CSO team ran 8-12 afterschool clubs in total, for which they prepared written program plans and individual weekly reflections.

\section{Afterschool Clubs - Creative Science Investigation}

(CSI). Within their assigned teams, CSO students began to conduct clubs at their assigned middle school around the time that LPS started their second quarter. CSO students were responsible for developing content for each hour-long club meeting, and for creating evaluation material for their club. Within their team, members rotated their roles weekly so that each CSO student had a turn at leading the club. One CLC staff member was always present during CSI clubs to oversee potential behavioral issues, but CSO students were responsible for all informal science learning.

Of note, three years after the program started, we extended the CSI clubs to include elementary school (ES) students. Funding from the Nebraska Department of Education (2016 - 2018) facilitated this extension. With this funding, MS students had the opportunity to teach scientific concepts to ES students during afterschool clubs. That is, CSO students taught MS students, and MS students taught ES students. This extension enhanced the reach of the integrated program by allowing MS students to gain experience as science educators, furthering their capacity for science learning and science identity formation. This extension was, however, difficult to sustain without funding as it required a full-time graduate student to coordinate all clubs and to supervise joint MS-ES clubs. Without funding, it is unlikely that we will be able to financially support a graduate student role and thus, 
the ES joint clubs have an unknown future. As such, we do not include evaluation results for this program extension.

Field trips. One important feature of the CSI clubs was two field trips to the UNL campus. During the first field trip, MS students toured laboratories in SBS and spoke with graduate students working in their labs about their science. During the second trip, MS students visited the UNSM where they worked with museum education specialists and science communication interns to practice skills for communicating science with the public in a museum context.

III. Sunday with a Junior Scientist (SWJS). SWJS was a public capstone event held at the UNSM at the end of each semester of the CSO course. During this event, the MS students became public science communicators, demonstrating the scientific knowledge that they gained in afterschool clubs to museum visitors. MS student families typically came to the event. To prepare, MS students worked with the CSO student leaders of their CSI club to choose club activities to present to the public. Often, but not always, club activities were variations of activities that CSO students had designed for their CSI clubs. The MS students were in charge of their stations, and the CSO students coached and assisted as needed during the event.

We added the SWJS element to our program in 2016 (Table 1), after the receipt of supplemental funds from the Nebraska Department of Education. Following this initial partnership, however, further funding was not required to sustain this event thanks to the generosity of the UNSM museum donors. Importantly, donor support allowed for free public admission to the event, enabling the families of MS students to attend regardless of their ability to pay.

\section{EVALUATION HYPOTHESES AND METHODOLOGY}

Hypotheses. We hypothesized that providing university students with opportunities to practice science communication outside of academia and to engage directly with the community would increase their science identity and their confidence in and motivation to pursue science. Additionally, we expected increased enthusiasm for and interest in informal science education among our CSO students. Similarly, we hypothesized that providing opportunities for MS students to work with university students in informal science learning activities, and to develop and share their knowledge through capstone events, would increase their interest in science, their understanding of science content, and their science identity. Figure 1 summarizes our program and highlights our expectations of increased measures of science identity, confidence, and motivation across both of our target audiences - university students (through CSO course) and MS students (through CSI clubs).

Evaluation Approach. We collaborated with the Methodology and Evaluation Research Core Facility (MERC) and the Bureau of Sociological Research (BOSR) at UNL to evaluate the integrated science-learning program. There were two external evaluations of the program: one that assessed outcomes after the first two years of the program (2013-2014) conducted by BOSR and one after the last two (2017-2019) conducted by MERC (BOSR, 2014; Hill and Whitney, 2019).

Course content and outcome measures differed between these two evaluations, yet the goals of each iteration were similar. Both sets of evaluation focused on two populations: (1) university students who enrolled in the CSO course and (2) the MS students who participated in the CSI clubs. The present study incorporates quantitative and qualitative data from these evaluation reports with course evaluation data across all nine offerings of CSO. Four CSO students also completed follow-up qualitative interviews.

\section{Evaluation of (I) Communicating Science through Outreach} (CSO) Students. The BOSR conducted surveys of CSO students during the initial NSF funding period (first phase: 2013 - 2014). MERC conducted surveys of CSO students during the Nebraska Department of Education grant funding periods (second phase: 2016 - 2019). Survey questions were less consistent across CSO courses during the first phase of evaluation (i.e. different questions were asked across different class offerings). Thus, we focus solely on CSO surveys from the second phase $(n=32)$, as identical surveys were conducted across all students.

In addition to the surveys, we administered formal course evaluations at the end of each semester (all nine-course offerings). The course evaluations, designed by the SBS and completed on a scantron sheet, contain both closed- and open- ended questions ( $\mathrm{n}=16$ and 5, respectively). Course evaluations were consistent across all phases of evaluation. One item on the course evaluation was directly relevant to this study; it related to students' perceptions of "outstandingly good" aspects of the course. Over the nine times the course was offered, a total of 71 students completed the course evaluations.

During the first evaluation phase, BOSR also conducted focus groups with CSO students to explore the impact of the class on their future professional goals involving science or science outreach, and to receive feedback about their experiences with the afterschool clubs and with the course as a whole. A total of 11 students participated in the focus groups in Spring of 2014.

Finally, at the end of the last funding cycle and thus last evaluation phase, we invited undergraduate and graduate students who had completed the CSO course to participate in 
follow-up interviews. We asked CSO students to reflect on their experiences as learners in the course, and to talk about the personal and professional impact of the CSO course on their current and future goals. We recruited alumni by word of mouth, personal invitation, and an email. We queried participants about four areas: (i) course procedures and content, (ii) learning objectives, (iii) future goals, and (iv) suggestions for instruction. Example interview questions included, "How did the course meet your expectations?" and "What were some key experiences in the club environment that made an impression on you?" Undergraduate students who were not involved in the project transcribed verbatim all interviews. Four former CSO students participated in the qualitative interviews ( 1 graduate student and 3 undergraduate students) which ranged in length from 22 to 40 minutes.

Evaluation of (II) Afterschool Clubs - Creative Science Investigation (CSI) Students (MS). During the first phase of evaluation, BOSR created a survey to gauge MS students' attitudes towards science. Additionally, CSO students created survey questions that were specific to their club's activities, which resulted in customized surveys for each club. Our analysis focuses only on four questions common across BOSR surveys. These questions focused on MS students' perceived understanding of science, scientists, and science career aspirations. To keep our results comparable across evaluation phases (see below), we collapsed positive responses together (e.g. very likely + likely + somewhat) and negative responses together (e.g. less likely + not at all). We then visualized the data using pie charts to demonstrate the proportion of responses that were positive versus negative. Between $n=31$ and $n=40$ MS students filled out surveys during the initial evaluation phase. We used a probability test to compare our observed proportion of positive responses to the random expectation of 50\% (JMP software; One-sided probability test).

During the second phase of evaluation of MS students, the MERC developed a pre-post survey for MS club attendees. Middle school students were asked to rate their level of agreement with a series of statements regarding their interest in science, understanding of science, and their science identity on a scale from 1 (strongly disagree) to 4 (strongly agree). We assessed the same general constructs related to understanding of science and science career aspirations in the second phase of evaluation as we did in the first. A total of $34 \mathrm{MS}$ students completed these surveys.

Similar to the procedure that we used to group responses during the first phase of the evaluation, we collapsed responses from the second phase into positive responses (strongly agree + agree) and negative responses (disagree + strongly disagree). For example, for the statement "Science is hard to understand", our positive response score summed "strongly disagree" + "disagree" and our negative response score summed "strongly agree" + "agree". We compared the positive responses (\%) from the start of the semester to the end of the semester by plotting them on a graph. Then, we used a one-tailed probability test to test the prediction that the proportion of students with positive responses would be higher after participating in the CSI club as compared to before (JMP Pro 15 software; one-sided probability test).

We did not conduct a formal evaluation of the SWJS event among public attendees. We also did not ask any SWJS-specific questions on CSO or MS surveys. CSO and MS students that participated in the SWJS event however, likely incorporated their experience at this event into their overall perception of the program.

Table 3. CSO student survey responses for the second phase of funding. Comparing the proportion of positive responses before and after the CSO course participation for University students (one-sided probability testing that 'after' is greater than 'before').

\begin{tabular}{|c|c|c|c|c|}
\hline & Sample Size & $\%$ Positive Before & \% Positive After & $P$-value \\
\hline \multicolumn{5}{|l|}{ Science Identity } \\
\hline How much, if at all, do you want to become a scientist? & 31 & 0.87 & 0.87 & 0.63 \\
\hline How much do other people think you are a science kind of person? & 32 & .906 & .903 & 0.67 \\
\hline How much do you think you are a science kind of person? & 31 & 1.00 & 0.97 & 0.99 \\
\hline \multicolumn{5}{|l|}{ Working with Youth } \\
\hline I can describe complex scientific phenomenon to youth. & 32 & 0.84 & 1.00 & $<0.0001$ \\
\hline How confident are you in working with kids? & 32 & 0.84 & 0.90 & 0.25 \\
\hline How much do you feel you are a role model? & 32 & 0.84 & 0.90 & 0.25 \\
\hline How interested are you in pursuing a career in education? & 32 & 0.38 & 0.52 & 0.08 \\
\hline \multicolumn{5}{|l|}{ Communication } \\
\hline How hard is it for you to communicate science? & 32 & 0.69 & 0.74 & 0.33 \\
\hline How comfortable do you feel presenting to groups? & 32 & 0.81 & 0.81 & 0.64 \\
\hline How important is communicating science to your future career? & 32 & 0.97 & 0.97 & 0.76 \\
\hline
\end{tabular}




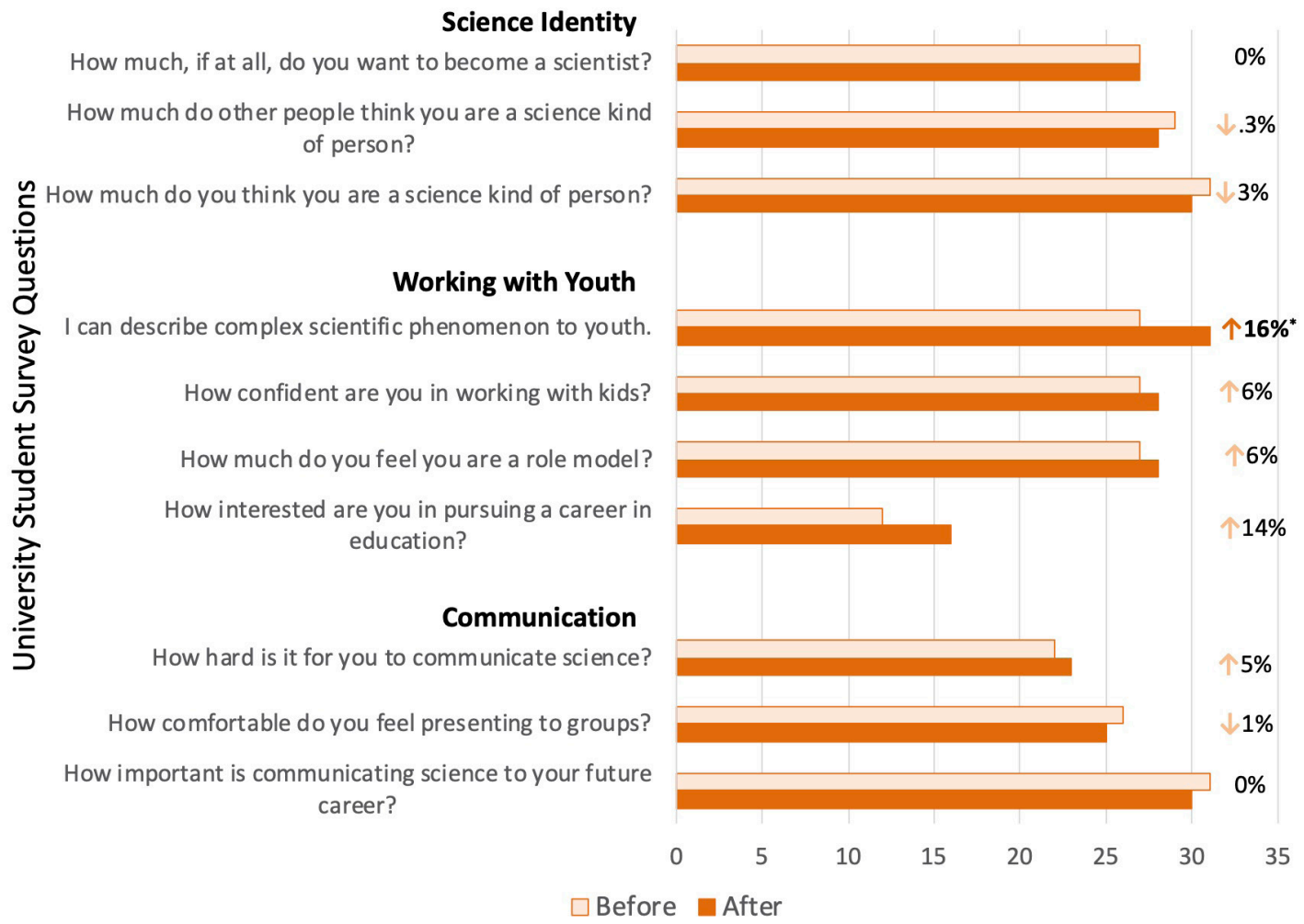

Figure 2. During the second funding phase (2016-2019), Communicating Science through Outreach (CSO) university students (graduate students + undergraduates) reported predominantly positive responses (the majority above $80 \%$; Table 3 ) to survey questions about science identity, working with youth, and communication ( $n=32$ responses for pre-survey questions, although two questions had $n=31 ; n=31$ responses for all post-survey questions; Table 3 ). Arrows indicate that some responses became qualitatively more positive at the end of the course (dark orange - after) as compared to the beginning of the course (light orange - before), but only one indicates a positive change (i.e. 'describe complex scientific phenomenon'; $p<0.0001$ ). Many responses remained the same.

\section{RESULTS}

\section{Communicating Science through Outreach (CSO).}

Survey Responses. The surveys for CSO students included items about students' confidence and motivation in three areas including - (a) science identity, (b) working with youth, and (c) communication. CSO student responses to questions about science identity were high prior to the start of the CSO course, and remained high after the course ( $>85 \%$ across all questions; Table 3). Similarly, most of the questions pertaining to working with youth started high (84\%), except for a relatively low proportion of students expressing an interest in a career in education ( $38 \%$; Table 3$)$.

CSO students' confidence and comfort in communicating science, and in their perception that science communication is important to their future career ranged between 70 to $97 \%$ positive across the course, and did not significantly differ from before to after the course (Table 3). Raw scores as well as percent changes in positive responses show in Figure 2. Importantly, there was a $16 \%$ increase in positive responses about science communication skills across the semester, indicating that students felt significantly more competent in describing complex scientific phenomenon to youth after the course (Table 3; Figure 2).
Open-Ended Responses. Another opportunity for CSO student feedback came from open-ended questions on the course evaluation. Student responses were generally positive with many students indicating that they enjoyed the way they were able to give and receive feedback about their lesson plans for CSI clubs from the other groups. In particular, CSO students noted that they liked the flexible structure of the course best. We synthesize representative comments to the question - Are there any outstandingly good features of this course - in Table 4. These results encompass seven offerings of the CSO course.

Focus Groups. CSO students who participated in focus groups reported positive attitudes about their understanding and confidence in science, their impact on MS youth, and their experiences in the course. Students were mixed in their responses to questions about future career goals in science. We categorized the focus group responses into themes including: (i) views on science understanding and confidence, (ii) perceived impact on MS students, (iii) future career goals, and (iv) general views on the course (Table 5). 
Table 4. Students responded positively to the end of the semester formal evaluation survey question "Are there any outstandingly good features of this course?"

Spring 2013

- "The main activity, designing and running the clubs, is the most outstandingly good feature of the course. Fantastic experience."

- "This is the best class I have taken at UNL."

- "This was my favorite course this semester. Highly interactive and engaging $\odot$ ")

- "Awesome course! One of my favorites! Fun, interesting and laid back, but I still learned a lot."

Fall 2014

- "YES! They won't fit on this page. There was a perfect balance of information given at the beginning and then we were able to apply

it. I loved going into schools."

- "The idea and content is excellent and helps students expand their horizons."

- "This course provides a great opportunity to try out activities for scientific outreach in a low-stress environment and then deliver those activities to young students in the community. This course is great for the students in it but also for students in the community."

- "I love how different this is from other courses. We were able to do something that most courses don't offer and I really enjoyed the interactions with the students."

Fall 2016

- "Opportunity to get real-life experience teaching."

- "This was an EXTREMELY rewarding class. It was my favorite of all undergrad and grad courses I have taken."

- "The connection with younger students was fantastic."

- "This is a great course to take if students are interested in outreach. Very rewarding to work with middle school students. Dr. Eileen Hebets is a great instructor!"

- "You really learn a lot about yourself during the course of the semester and you get to positively impact young student lives."

- "This is an outstanding course and I'm sad it's only for a semester."

- "This was a really good and well-planned course that gave unique opportunities. Dr. Hebets did a wonderful job making outreach fun."

- "The interactive nature of the course is very helpful in the learning process."

- "We get to learn about informal science education by doing it."

\section{Spring 2017}

- "Unique experience that is otherwise unavailable. Could be really valuable to those interested in outreach, but that is not always achieved."

- "Great to have the opportunity to work in after-school environment."

Fall 2017

- "I liked how we would present our lesson plans in class and go through the activities as a test run, I got great advice from it."

- "Yes, this course has been one of my favorites at UNL because it is so hands-on and interactive. I learned a great deal all semester that is extremely relevant to my major."

- "I recommend this class to everyone. It was one of the best and valuable classes I've taken at UNL."

Spring 2018

- "Great Class! Got me interested in a new career path. I will definitely recommend it in the future."

- "So fun getting to teach and watch the students' interest grow during each club."

- "This has easily been one of my favorite classes I've taken at UNL. I learned just as much about myself as I did with the kids."

- "I would recommend this class to anyone - no matter what they think/feel about education. This has made me so much more comfortable with middle school aged kids and reminded myself why science is so interesting and important to me."

- "Yes - it is a GREAT Course. It allows you to volunteer in a setting where you get to interact with the kids and teach them science. I've become a lot more comfortable with kids and hope to continue this outreach work."

\section{Spring 2019}

- "I really enjoyed being able to teach the kids science topics and see them grow. I also improved many aspects of myself after this class."

- "I really enjoyed working with the kids and creating the program plans." 
Table 5. CSO university student quotes from focus groups.

\section{(i) Views on Science Understanding and Confidence}

“[the outreach experience] didn't affect my deep knowledge, but I did have to learn about lesson plans, and interesting factoids."

Made them think about "what is obvious in science and what is not obvious in science, especially when you've been working in the field for a really long time."

"On my part at least, I knew a lot of the stuff and I always like to share the same stuff because I know what activities worked."

"Most of the activities forced me to broaden my knowledge on some things that I normally wouldn't necessarily be interested in or was apprehensive about learning."

"Having another group helped me to broaden my knowledge. Looking at the activities that the other group did, helped me to step back and open my mind to other types of activities that would also work."

"Scientists need to remember that they aren't talking to scientists...you really have to stop and think for a moment about what you're really trying to say and break it down to its core component and it's tough, really tough."

\section{(ii) Perceived impact on MS students}

each week their club was "growing, and definitely not shrinking" indicating that interest was spreading outside the initial group of kids who were attending.

"kids were starting to understand the concepts of costs and benefits of certain groups in biological systems...starting to understand why that's important and it's how biology really works."

"some were really growing, and some of our students don't really seem to be changing at all."

"it was about trying to get them to not say "eww."”

\section{(iii) Future Career Goals}

"I don't want to be a middle school science teacher full-time. It's so much work."

simplifying the material for the younger audience was not desirable, "the part of biology that I do that's really cool is too complicated for younger students to understand."

"[I] really liked the middle school experience. There's payoff; I'll never be able to explain like the RNA sequence...there are things that are so much cooler than what you're doing...but looking at how the only kids who are going to join our club...it's such an important time to show kids this stuff and give them enough interest to get over the hump of eighth grade."

"I had thoughts about it before class (middle school teacher). I just can't imagine middle school if I go into teaching. I think I'd do high school or community college instead."

"I underestimated middle schoolers. I want to keep up this outreach in the future and keep in mind middle school teaching as an option for a career."

\section{(iv) Overall course views}

"Like having the freedom to teach the kids about whatever we were interested in...that way we would be passionate about what we were teaching too."

"there was a lack of structure within a structure."

"I really liked how we were allowed to get feedback from the other groups...we were allowed to practice in here and get feedback."

"it's a lot harder to bring some things that I think are in higher education almost taken for granted and expected to lay persons and to make it relatable."

"You have to take what you think is simple and basic and break it down into something more simple and basic."

"Seems really important to have at least one sentence that relates what you're teaching to their life."

Qualitative Interviews. We used thematic analysis to analyze the qualitative interview transcripts (Braun et al., 2019; Vaismoradi et al., 2016). Thematic analysis is an approach to analyzing qualitative data where the aim is to identify the shared meaning of an experience across participants rather than to highlight individual meanings. There were three common themes about experiences within the CSO course that the participants shared: relationship-building, inspiring young learners, and preparing for the future.

Relationship-building. Each interview participant identified relationship-building as a key factor in effectively communicating science to MS students. When CSO students established interpersonal connections with the MS students, they perceived themselves as effective instructors of scientific concepts. CSO students also relied on relationships to help MS students focus on science learning instead of social distractions. For instance, one CSO student shared, "We only had three students and one of them was difficult. Some days...she just didn't want to do anything. Well, she really liked me. I would just sit with her, just being really supportive. I think that really helped because then she would get over it and get excited about the activity." Other CSO students echoed this sentiment, describing instances in which they used interpersonal skills such as gaining trust, reading non-verbal cues, and active listening to keep the club orga- 
nized and engaging.

Developing relationships with students was beneficial, but it did not come easily to all CSO students. Some described their anxiety around interacting with MS students, and finding a way to teach scientific concepts without using disciplinary jargon. For instance, a CSO student stated that, "I'm not actually very good with kids... I just thought it'd be really fun to come up with scientific activities because part of science is reaching out to other people and expanding their knowledge. I think that it's really hard to do when you're a grad student unless you have opportunities like this where you can work one on one with kids or with a group of kids." Though challenging, the CSO students found that the course had a powerful impact on their personal and professional lives as well as on the lives of the students who attended the clubs.

Inspiring Young Learners. Inspiring MS students to learn about science and to consider science-related careers was a principal focus among the CSO students. They did this by being credible role models, and by explicitly deconstructing stereotypes about scientists. For instance, one CSO student recalled that, " $A$ kid who told us at the beginning of the club, 'I'm just going to work at Amigo's [a local restaurant chain] for the rest of my life.' And then by the end of the club he was like, 'I think I'm going to get my mechanic's degree."”

All of the CSO students indicated their intention to provide MS students with access to science education, particularly those who might be underrepresented in STEM fields. One CSO student observed that, "My first semester was really impactful because we had a lot of kids that were told they weren't good enough for college. We were like, 'but you are good enough for college! " The CSO students described feeling that they made a difference in MS students' lives, and that feeling prompted them to find additional opportunities to get involved in the community, particularly with informal science education programs.

CSO students also made efforts to address stereotypes in science by investigating young learners' understanding of scientists through a fun activity and discussion. They aimed to understand what the MS students believed scientists look like (e.g. male, white coat, etc.), and do (e.g. work in a laboratory, conduct experiments) by asking them to use paper materials to craft a scientist. The images guided CSO students to gently challenge learners' preconceptions, and offer alternative and more inclusive notions of scientists. For example, the leaders told stories about how they became graduate students, and got interested in science, "So they get to see, 'oh wow! These people are scientists! And that's pretty cool... what does that mean and how do we get there?" CSO students purposefully drew attention to their 'ordinary dress' and diverse backgrounds, demonstrating to MS students that science is accessible to everyone.

Preparing for the Future. Participants emphasized that, as scientists, they feel responsible to communicate their work in meaningful ways beyond the university setting. By working with MS students, they perceived that they gained skills in science communication that will benefit them in future careers. For example, one student reflected that, "If I'm just doing my science and staring at a computer, it's very different from going out there and getting people excited and learning." Another CSO student shared that, "If you're going to be a researcher, it's a good class to take because you're going to get those skills ... thinking about 'how do I bring this down to a different level without jargon?" The finding that CSO students perceived an increase in their science communication skills aligns with findings from the quantitative survey, reinforcing the suggestion that the CSO course was an effective way to teach science communication.

In addition to science-communication skills, the CSO course influenced students' planning for the future. Participants expressed that the experiences they had in clubs either added to established plans to engage in science communication, or introduced new ideas about potential career paths they had not yet considered. For instance, one CSO student stated, "I had never actually thought to do any sort of science communication work...I really enjoyed it." Another shared, "I think it solidified that I'm going down the right path. I think I'll branch off and work more with teachers... It showed me that this is what I really enjoy doing." Each participant commented on the relevance of the course

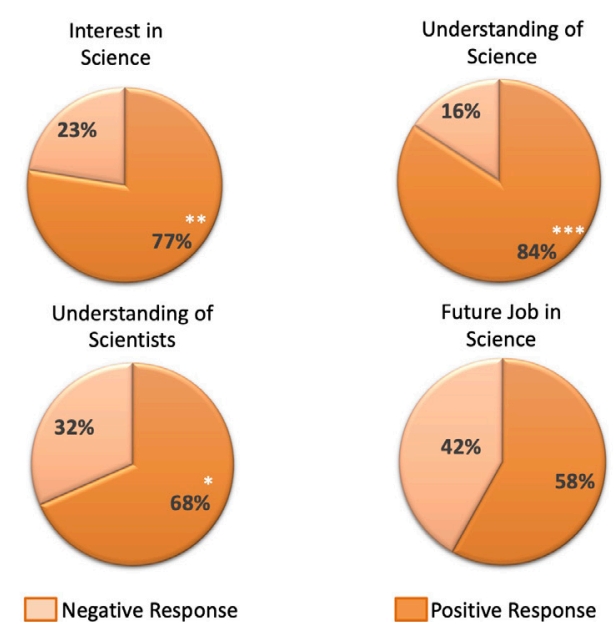

Figure 3. During the first phase of evaluation (2013-2014) middle school students reported a positive interest (dark orange) in science $(n=40)$, understanding of science $(n=38)$, understanding of scientists $(n=38)$, and interest in a future job in science $(n=31)$ at the end of their semester-long afterschool clubs. Their interested was significantly higher than expected by chance alone (i.e. $50 \%$ ) for their response to interest in science $\left({ }^{* *} p=0.0003\right)$, understanding of science $\left({ }^{* * *} p<0.0001\right)$, and understanding of scientists $\left({ }^{*} p=0.017\right)$. 
Table 6. Comparing the proportion of positive responses before and after the CSI club participation for MS students (one-sided probability testing that 'after' is greater than 'before').

\begin{tabular}{llccc}
\hline & $\begin{array}{l}\text { Sample } \\
\text { Size }\end{array}$ & $\begin{array}{l}\text { \% Positive } \\
\text { Before }\end{array}$ & $\begin{array}{l}\text { \% Positive } \\
\text { After }\end{array}$ & P-value \\
\hline $\begin{array}{l}\text { I want a career in } \\
\text { science }\end{array}$ & 34 & .53 & .79 & $\mathbf{0 . 0 0 0 5}$ \\
$\begin{array}{l}\text { Others see me as a } \\
\text { scientist }\end{array}$ & 33 & .27 & .63 & $\mathbf{< 0 . 0 0 0 1}$ \\
$\begin{array}{l}\text { I am a science kind of } \\
\text { person }\end{array}$ & 34 & .79 & .88 & 0.14 \\
$\begin{array}{l}\text { Science is hard to } \\
\text { understand }\end{array}$ & 35 & .46 & .35 & 0.93 \\
$\begin{array}{l}\text { I am excited to learn } \\
\text { about science }\end{array}$ & 34 & .97 & .97 & 0.73 \\
I enjoy doing science & 35 & .97 & .97 & 0.73 \\
\hline
\end{tabular}

to their personal and professional growth, underscoring the importance of moving their work out of the laboratory and into the public space.

\section{Afterschool Clubs - Creative Science Investigation (CSI).}

Survey Results. Because of shifting attendance throughout the CSI clubs (the same students that took the pre-club survey were not necessarily the same students that took the post-club survey), we only analyzed post-club surveys. There were between 31 and 40 MS students who completed questions on the BOSR post-course survey during the first phase of evaluation. The most positive responses related to students' understanding of science and interest in science ( $84 \%$ and $77 \%$ respectively) while $58 \%$ of MS students expressed an interest in a future job in science (Figure 3). Students responded more positively than expected by chance alone (i.e. $>50 \%$ ) to the statements about interest in science, understanding of science, and understanding of scientists, but not to the statement regarding a future job in science (Figure 3).

There were between 33 and 35 MS students who completed the post-club survey on their attitudes toward science and science aspirations during the second phase of evaluation (although some students did not respond to all questions) (Table 6). Middle school students reported a significant increase in their desire to pursue a career in science (an increase of 26\%) and an even larger increase in one component of their science identity (Table 6; Figure 4). Specifically, they responded $35 \%$ more positively to the statement "Others see me as a scientist" (Figure 4). There was also an increase in students' perceptions about being a "science kind of person" (increased 8\%), but this was not a significant increase. There were no differences, however, across students' perceptions about their excitement to learn science, their understanding of science, or their enjoyment of science.
Anecdotal Results. In addition to the formal data that we collected throughout this project, anecdotal information provided to the Lincoln CLC science curriculum coordinator (KP), to course instructors (EAH and TBC) and/or the museum director (SW) contributed valuable feedback to the team.

During final presentations for the CSO course, university students shared their experiences with planning and implementing clubs. Several of these students (some of whom were graduate students) said that this experience changed their life. They indicated that because of this experience, they would in some way make community outreach a part of their professional life. Two of the students said that they decided to change their professional course by pursuing a teaching degree.

Many MS students verbally reported that the field trips to visit UNL's SBS laboratories to see scientists at work was their favorite part of the CSI club. Some of the scientists who participated (most of whom were graduate students) were also leaders of the CSI clubs and represented a diverse population, enabling MS students to expand their vision of who can be a scientist. This is important because one of the challenges in recruiting and maintaining a skilled and inclusive STEM workforce relates to students' science identities and whether they see themselves reflected in the field (e.g. Hazari et al., 2013; Hill et al., 2017).

The MS students appeared to enjoy their weekly interactions with CSO students. At the end of the CSI club, CSO students reported to their instructor that their MS students displayed strong emotions about parting with their club leaders. It was clear that many positive relationships had formed between CSO and MS students.

In addition to enjoying the supportive relationships that

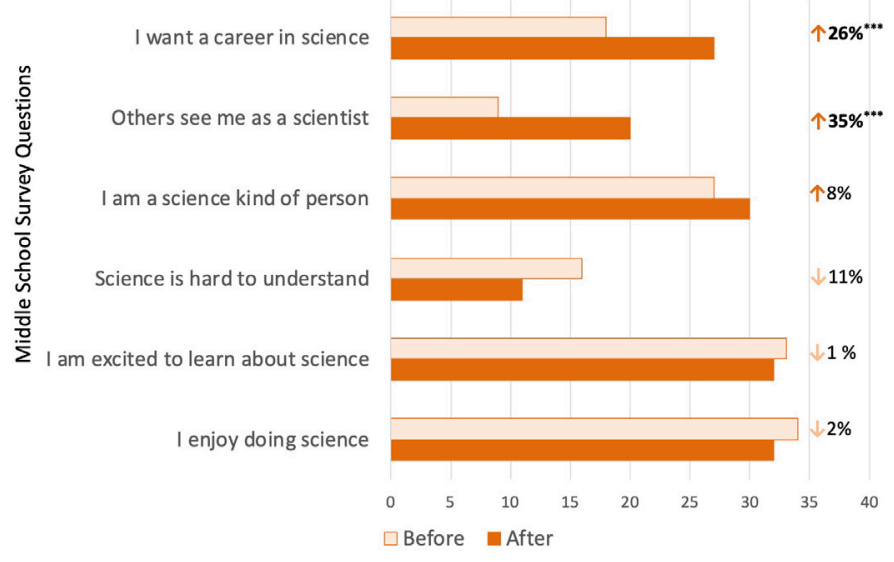

Figure 4. During the second phase of evaluation (2016-2019), middle school students showed a significant increase in positive responses to the statements 'I wanting a career in science' $\left({ }^{* * *} p=0.0005\right)$ and 'Others see me as a scientist' $\left({ }^{* * *} p=0.0005\right)$. None of the other statements showed a significant increase or decrease when comparing the before and after responses (Table 6). 
they found within clubs, MS students seemed to benefit cognitively and socially from the SWJS event each semester. The public response was also very positive and despite not requesting formal feedback, many people expressed appreciation in museum visitor surveys.

\section{DISCUSSION}

We aimed to create a sustainable service-learning community around science education by integrating existing formal and informal educational structures at multiple educational levels. The goals of this integrated science-learning program were to increase science learning and science identity among university and MS students in order to boost their interest and confidence in science, and to motivate them to persist in STEM. To do that, we created a university-level service-learning course, $\mathrm{CSO}$, as a means to deliver high-quality informal science education to MS students within (predominantly) Title I schools. Overall, we found that students at all educational levels benefited from the program. Here we discuss the benefits for each educational cohort.

University (CSO) Students. We found that the service-learning format bolstered university students' perceptions about their ability to communicate science and deepened their identification with their STEM fields. Specifically, we observed that CSO students entered the course with a high-level of science identity and that high-level was maintained throughout the course. We found similar results for CSO students' perceptions of their ability to communicate science and their feeling that science communication is important.

One area where CSO students demonstrated significant growth related to working with youth. We found a statistically significant increase in CSO students' self-reported ability to describe scientific phenomenon to youth, and confidence in working with youth. In responses to open-ended questions on course evaluations, the underlying thread was that this course was a unique opportunity for students to practice science in an informal setting that felt less stressful than it might in a traditional classroom setting (see Table 4). Moreover, several of the CSO students stated that they enjoyed working with kids, and that they perceived themselves as role models to the MS students.

By the end of the program, CSO students indicated a greater interest in pursuing a career in education. Though this particular finding was not statistically significant, it demonstrates some change in how students consider future career options. Several CSO students reported in formal evaluations and interviews that the course inspired them to think about their future careers and about how science communication and outreach might fit in their plans for working in the STEM field. We expect, as found by others (Ufnar et al. 2012), that the increased confidence students gained in association with this experience will persist and will influence future career choices.

Qualitative interviews shed light on how the CSO students managed their clubs and why they felt that their experiences with MS students were meaningful. For instance, we learned that the interpersonal relationships that CSO students formed with the MS students during club time helped them to create a space where MS students could ask questions and interact in an authentic way. Some CSO students expressed surprise about the effort that MS students made to attend club and to attend the SWJS event. For example, one CSO student recalled that his MS student and her family did not have transportation to the SWJS event. They paid for a shared ride service even though they were a low-income family, signaling the significance of that event for the MS student. This importance of establishing relationships in informal science education that we found is similar to prior research by Clarke-Midura and colleagues (2018) who reported that science educators' relatability relates to young learners' science-related interest and self-efficacy. This was evident in our participants. These types of personal experiences are those that make service-learning valuable because they demonstrate the importance of applying classroom learning in 'real-world' settings.

MS Students. Like the CSO students, the MS students who attended the CSI clubs made significant gains across most programmatic objectives. Middle school participants were already excited about and enjoyed science when they started the clubs, yet they appeared to have an underdeveloped sense of science identity. This sense of identity is an important factor in science persistence, and it improved for MS students across the program. Middle school students participating in the club left feeling interested in science, having a perceived stronger understanding of science, and stronger understanding of who scientists are and what they do. Our findings support previous research showing that informal science experiences in out-of-school settings reinforce and complement formal science learning, and engage youth in a more relaxed setting that may facilitate their enjoyment of science (Banerjee, 2017; Dabney et al., 2012; Trujillo and Tanner, 2014).

Across both evaluation phases, more than $50 \%$ of participating students expressed an interest in a STEM career and this coincided with even higher reports of excitement about learning science, enjoyment of doing science, and being a "science kind of person", among others. These findings align with research that shows that a science identity and a science possible self are associated with desiring a career in science in adolescence (Buday et al., 2012; Dabney et al., 2012; Hill et al., 2017). Interestingly, though MS student responses were similar across evaluation phases, we saw significant in- 
creases in "others see me as a scientist" and "I want a career in science" in the second phase of evaluation.

During our second phase of evaluation, 53\% of MS students initially responded positively to wanting a career in science (Table 6), which was similar to our post-club response of $58 \%$ in phase one of evaluation (Figure 3). This number increased by $26 \%$, up to $79 \%$ of MS respondents, after the CSI club participation in phase two (Table 6, Figure 4). Similarly, in phase two, $62 \%$ of MS students responded positively to "Others see me as a scientist", which was an increase of $35 \%$ (Figure 4). Numerous potential reasons exist for these significantly high positive post-club responses in phase two, but not phase one, of our evaluation - e.g. differences in the manner in which we asked the questions, differences among the students themselves (e.g. demographic differences; grade-level differences; etc.), among others. Unfortunately, we are unable to evaluate these. Notably, one program component was present during the second phase of evaluation, but not the first - the SWJS event. This capstone event provided an opportunity for MS students to be the experts, the scientists, the teachers, and to take on this role in front of their peers and their families.

We hypothesize that participation in the SWJS event may be responsible for our observed increase in science identity and interest in science-related careers in our second phase of evaluation. Museum staff engaged family members during the event, and anecdotally reported many conversations with family about their pride in the students' achievements. Free public admission to the event enabled the families of students who presented to attend the event, regardless of their ability to pay. The involvement of family members may have played a large role in the reported increases in science identity and career aspirations in our second phase of evaluation.

Science identity is a precursor to science career aspirations, and middle school has been identified as a critical developmental period when youth science identities are likely to be in flux (Carlone et al., 2014; Vedder et al., 2012). Young students' perceptions of what scientists look like and what they do might bear on their future educational and career choices (Buldu, 2006; Wyss et al., 2012; Zeldin and Pajares, 2000). Those that fail to see themselves reflected in stereotypical images of scientists might be less likely to join the STEM field (Cheryan, et al., 2009; Cheryan et al., 2015). Through this service-learning course, CSO students directly challenged stereotypical frames of scientists, pushing MS students to envision themselves as capable of joining the STEM field. Our results suggest that this approach was successful. Our results further suggest that an interesting avenue for future research might involve exploring the impact of various audiences (e.g. family vs. non-family) during programming aimed at empowering youth to see themselves as scientists; and/or the role of family attitudes in supporting students' science identity and aspirations. Future research on approaches that shift young students' thinking about scientists remains a critical goal as well.

Sustainability. At a minimum, replication of this program at another university would require the interest and support of a STEM faculty member who values service learning. This is non-trivial as such faculty can be difficult to find. Additional requirements include the interest, support, and collaboration of local public or private K-12 schools, associated teachers and staff, as well as interest among both university students and MS students.

\section{CONCLUSIONS}

Our findings fit within the broader literature regarding factors that relate to an enduring drive to persist in the STEM fields (Dabney et al., 2012). Educational interventions are effective means to bolster students' science identity and consequently, their interest in a future science career (e.g. Hernandez et al., 2013, this study). Moreover, positive effects of the CSO course and associated programming extended beyond university students to reach MS students, underscoring the value of integrating programs across educational levels.

This integrated science-learning program was successful over the course of more than seven years, despite limited and intermittent funding. External grant funding is now unnecessary at this point in the program, as the course is now fully integrated into the University of Nebraska-Lincoln's School of Biological Sciences curriculum, and the partnership with the Lincoln CLCs and UNSM is strong. This program is sustainable indefinitely as long as (a) there are faculty willing to teach the course, (b) students willing to take the course, and (c) a continued strong partnership with the Lincoln CLCs and the University of Nebraska State Museum.

\section{ASSOCIATED CONTENT}

Supplemental material mentioned in this manuscript can be found uploaded to the same webpage as this the manuscript.

\section{AUTHOR INFORMATION Corresponding Author}

Eileen A. Hebets. Ehebets2@unl.edu

\section{Author Contributions}

The manuscript was written through contributions of all authors. All authors have given approval to the final version of the manuscript. 


\section{ACKNOWLEDGMENTS}

We thank UNL's School of Biological Sciences Directors John Osterman and Mike Herman and Lincoln Community Learning Center Director Nola Derby-Bennet for their support of this program. We also thank University of Nebraska State Museum Education Supervisors Kathy French and Jennifer Ruyle for their help working with MS students and coordinating and running SWJS. Judy Diamond was instrumental in both helping EAH acquire initial funding as well as in helping run the first CSO course. We also thank all of the CSO students, past instructors (Alissa Anderson) and MS students that participated in this program.

\section{FUNDING SOURCES}

We received support for this program from a National Science Foundation (NSF) grant (CRPA; DRL 1241482) and from two Nebraska Department of Education grants.

\section{ABBREVIATIONS}

AAAS: American Association for the Advancement of Science; BOSR: Bureau of Sociological Research; CLC: Community Learning Center; CRPA: Connecting Researchers and Public Audiences; CSI: Creative Science Investigation; CSO: Communicating Science through Outreach; EAH: Eileen A. Hebets; ES: Elementary School; ISL: Informal Science Learning; KP: Kathie Phillips; LPS: Lincoln Public Schools; MERC: Methodology and Evaluation Research Core Facility; MS: Middle School; SBS: School of Biological Sciences; STEM: Science, Technology, Engineering, and Mathematics; SW:Susan Weller; SWJS: Sunday with a Junior Scientist; UNSM: University of Nebraska State Museum

\section{REFERENCES}

AAAS. (2011). Vision and Change in Undergraduate Biology Education: A Call to Action. American Association for the Advancement of Science. [Accessed 31 May 2020] https://live-visionandchange.pantheonsite.io/wp-content/ uploads/2013/11/aaas-VISchange-web1113.pdf

AAAS. (2015). Vision and Change in Undergraduate Biology Educaiton Chronicling Change, Inspriring the Future. American Association for the Advancement of Science. [Accessed 31 May 2020] https://live-visionandchange. pantheonsite.io/wp-content/uploads/2015/07/VISchange2015_webFin.pdf

AAAS. (2018). Vision and Change: Unpacking a Movement and Sharing Lessons Learned. American Association for the Advancement of Science. [Accessed 31 May 2020] https://live-visionandchange.pantheonsite.io/wp-content/ uploads/2018/09/VandC-2018-finrr.pdf
Afterschool Alert. (2010). Afterschool: Middle School and Science, Technology, Engineering and Math (STEM). [Accessed 31 May 2020] http://afterschoolalliance.org/documents/issue_briefs/issue_stem_44.pdf

Afterschool Alliance. (2016). The Growing Importance of Afterschool for Rural Communities. [Accessed 31 May 2020] http://www.afterschoolalliance.org/AA3PM/Afterschool_ in_Rural_Communities.pdf

Atkinson, R., and Mayo, M. (2010). Refueling the US innovation economy: Fresh approaches to science, technology, engineering and mathematics (STEM) education. The Information and Technology Innovation Foundation. [Accessed 31 May 2020] https://itif.org/files/2010-refueling-innovation-economy.pdf

Banerjee, P. A. (2017). Is informal education the answer to increasing and widening participation in STEM education? Review of Education, 5(2), 202-224.

Blank, R. K. (2013). Science instructional time is declining in elementary schools: What are the implications for student achievement and closing the gap? Science Education, 97(6), 830-847.

Blue, J., and Gann, D. (2008). When do girls lose interest in math and science? Science Scope, 32(2), 44 - 47.

Braun, V., Clarke, V., Hayfield, N., and Terry, G. (2019). Thematic analysis. In L. Pranee (Eds.), Handbook of research methods in health social sciences, (pp. 843-860). Spring Science.

Bringle, R. G., and Hatcher, J. A. (1995). A service-learning curriculum for faculty.

Bringle, R. G., Ruiz, A. I., Brown, M. A., and Reeb, R. N. (2016). Enhancing the psychology curriculum through service learning. Psychology Learning \& Teaching, 15(3), 294309.

Buday, S. K., Stake, J. E., and Peterson, Z. D. (2012). Gender and the choice of a science career: The impact of social support and possible selves. Sex Roles, 66(3-4), 197-209.

Buldu, M. (2006). Young children's perceptionsof scientists: a preliminary study. Educational Research, 48(1), 121-132.

Bureau of Sociological Research (BOSR) (2014). Eight-Legged Educators: Exploiting the Enigmatic Nature of Arachnids. [Accessed 31 May 2020] https://www.informalscience. org/final-project-evaluation-informal-education-arachnids

Carlone, H. B., Scott, C. M., and Lowder, C. (2014). Becoming (Less) Scientific: A Longitudinal Study of Students' Identity Work From Elementary to Middle School Science. Journal of Research in Science Teaching, 51(7), 836-869. doi:10.1002/tea.21150

Cheryan, S., Master, A., and Meltzoff, A. N. (2015). Cultural stereotypes as gatekeepers: Increasing girls' interest in computer science and engineering by diversifying stereotypes. Frontiers in Psychology, 6, 49. 
Cheryan, S., Plaut, V. C., Davies, P. G., and Steele, C. M. (2009). Ambient belonging: how stereotypical cues impact gender participation in computer science. Journal of Personality and Social Psychology, 97(6), 1045.

Clarke-Midura, J., Poole, F., Pantic, K., Hamilton, M., Sun, C., and Allan, V. (2018). How near peer mentoring affects middle school mentees. Paper presented at the Proceedings of the 49th ACM Technical Symposium on Computer Science Education.

Dabney, K. P., Tai, R.H., Almarode, J.T., Miller-Friedmann, J.L., Sonnert, G., Sadler, P.M., and Hazari, Z. (2012). Out of school time science activities and their association with career interest in STEM. International Journal of Science Education, Part B: Communication and Public Engagement, 2, 63 - 79 .

Dudo, A., and Besley, J. C. (2016). Scientists' prioritization of communication objectives for public engagement. Plos One, 11(2), e0148867.

Furco, A. (1996). Service-learning: A balanced approach to experiential education. The Corporation for National Service. [Accessed 31 May 2020] https://digitalcommons.unomaha.edu/cgi/viewcontent.cgi?article $=1104 \&$ context $=$ slceslgen

Graham, M. J., Frederick, J., Byars-Winston, A., Hunter, A. B., and Handelsman, J. (2013). Increasing persistence of college students in STEM. Science, 341(6153), 1455-1456. doi: $10.1126 /$ science. 1240487

Hatcher, J. A., and Studer, M. L. (2015). Service-learning and philanthropy: Implications for course design. Theory into Practice, 54(1), 11-19.

Hazari, Z., Sadler, P. M., and Sonnert, G. (2013). The science identity of college students: exploring the intersection of gender, race, and ethnicity. Journal of College Science Teaching, 42, 82 - 91 .

Hebets, E. A. (2018). A Scientist's Guide to Impactful Science Communication: A Priori Goals, Collaborative Assessment, and Engagement with Youth. Bioessays, 0(0), 1800084. doi:doi:10.1002/bies.201800084

Hernandez, P. R., Schultz, P., Estrada, M., Woodcock, A., and Chance, R. C. (2013). Sustaining optimal motivation: A longitudinal analysis of interventions to broaden participation of underrepresented students in STEM. Journal of Educational Psychology, 105(1), 89.

Hill, P. W., McQuillan, J., Spiegel, A. N., and Diamond, J. (2018). Discovery orientation, cognitive schemas, and disparities in science identity in early adolescence. Sociological Perspectives, 61(1), 99-125. doi:10.1177/0731121417724774

Hill, P. W., McQuillan, J., Talbert, E., Spiegel, A. N., Gauthier, G. R., and Diamond, J. (2017). Science possible selves and the desire to be a scientist: mindsets, gender bias, and confidence during early adolescence. Social Science, 6. doi:10.3390/socsci6020055
Hill, P. W., Weber, E., Galdamez, M. and Whitney, C. (2019). VISLO: Vertically Integrated Science Learning Opportunity Summative Evaluation Report. [Accessed 31 May 2020] https:/www.informalscience.org/user/1650/resourcelist

Holstead, J., and King, M. H. (2011). High-quality 21st century community learning centers: Academic achievement among frequent participants and non-participants. Journal of Education for Students Placed at Risk (JESPAR), 16(4), 255-274.

Huda, M., Jasmi, K. A., Alas, Y., Qodriah, S. L., Dacholfany, M. I., and Jamsari, E. A. (2018). Empowering civic responsibility: Insights from service learning. In S. Burton (Eds.), Engaged Scholarship and Civic Responsibility in Higher Education (pp. 144-165). IGI Global.

Krishnamurthi, A., Ballard, M., and Noam, G. G. (2014). Examining the impact of afterschool STEM programs. Afterschool Alliance.

Linn, M. C., Palmer, E., Baranger, A., Gerard, E., and Stone, E. (2015). Undergraduate research experiences: Impacts and opportunities. Science, 347(6222). doi:10.1126/science. 1261757

Mackenzie, S. L., Hinchey, D. M., and Cornforth, K. P. (2019). A public health service-learning capstone: Ideal for students, academia and community. Frontiers in public health, 7, 10.

Maltese, A. V., and Tai, R. H. (2010). Eyeballs in the fridge: sources of early interest in science. International Journal of Science Education, 32(5), 669-685.

McCarthy, B. (1990). Using the 4MAT system to bring learning styles to schools. Educational Leadership, 48(2), 31-37.

McGinley, M. (2018). University Students Teaching Environmental Science to Primary School Students as Service-Learning: Lessons Learned. Paper presented at the SHS Web of Conferences.

Mclean, M., Mcbeath, J., Susko, T., Harlow, D., and Bianchini, J. (2019). University-elementary school partnerships: Analyzing the impact of a service-learning freshman engineering course on students' engineering values and competence beliefs. International Journal of Engineering Education, 35(5), 1415-1424.

Metz, A. M., and McLaughlin, J. (2016). Vision and change: Why it matters. American Biology Teacher, 78, 456 - 462.

Murphy, C., and Beggs, J. (2003). Children's perceptions of school science. School Science Review, 84, 109-116.

Najmr, S., Chae, J., Greenberg, M. L., Bowman, C., Harkavy, I., and Maeyer, J. R. (2018). A service-learning chemistry course as a model to improve undergraduate scientific communication skills. Journal of Chemical Education, 95(4), 528-534.

Sewry, J. D., and Paphitis, S. A. (2018). Meeting important educational goals for chemistry through service-learning. Chemistry Education Research and Practice, 19(3), 973-982. 
Shernoff, D. J. (2010). Engagement in afterschool programs as a predictor of social competence and academic performance. American Journal of Community Psychology, 45(3-4), 325-337.

Sorge, C. (2007). What happens? Relationship of age and gender with science attitudes from elementary to middle school. Science Education, 16(2), 33-37.

Tan, E., Barton, A. C., Kang, H., and O’Neill, T. (2013). Desiring a career in STEM-related fields: How middle school girls articulate and negotiate identities-in-practice in science. Journal of Research in Science Teaching, 50(10), 11431179. doi:10.1002/tea. 21123

Trujillo, G., and Tanner, K. D. (2014). Considering the role of affect in learning: Monitoring students' self-efficacy, sense of belonging, and science identity. CBE-Life Sciences Education, 13(1), 6-15.

Ufnar, J.A., Kuner, S., and Shepherd V.L. (2012). Moving beyond GK-12. CBE-Life Sciences Education, 11, 239-247.

Vaismoradi, M., Jones, J., Turunen, H., and Snelgrove, S. (2016). Theme development in qualitative content analysis and thematic analysis, Journal of Nursing Education and Practice, 6(5), 100-110.

Vedder-Weiss, D., and Fortus, D. (2012). Adolescents' declining motivation to learn science: A follow-up study. Journal of Research in Science Teaching, 49(9), 1057-1095.

Weiler, L., Haddock, S., Zimmerman, T. S., Krafchick, J., Henry, K., and Rudisill, S. (2013). Benefits derived by college students from mentoring at-risk youth in a service-learning course. American Journal of Community Psychology, 52(3-4), 236-248.

Woodley, S. K., Freeman, P. E., and Ricketts, T. D. (2019). Combining novel research and community-engaged learning in an undergraduate physiology laboratory course. Advances in Physiology Education, 43(2), 110-120.

Wyss, V. L., Heulskamp, D., and Siebert, C. J. (2012). Increasing middle school student interest in STEM careers with videos of scientists. International Journal of Environmental and Science Education, 7(4), 501-522.

Yang, J., LaBounty, T. J., Ekker, S. C., and Pierret, C. (2016). Students being and becoming scientists: measured success in a novel science education partnership. Palgrave communications, 2(1), 1-9.

Yusop, F. D., and Correia, A. P. (2014). On becoming a civicminded instructional designer: An ethnographic study of an instructional design experience. British Journal of Educational Technology, 45(5), 782-792.

Zeldin, A. L., and Pajares, F. (2000). Against the odds: Self-efficacy beliefs of women in mathematical, scientific, and technological careers. American Educational Research Journal, 37(1), 215-246. 